\title{
Electrochemical Evaluation of the Antioxidant Capacity of Phenolic Compounds in Virgin Olive Oil
}

\author{
Mourhat $\mathbf{Z}^{1}$, Touzara $\mathbf{S}^{2}$, Maallah $\mathbf{R}^{2}$, Mbarki $\mathbf{M}^{1}$ and Chtaini $\mathbf{A}^{2 *}$
}

${ }^{1}$ Transdisciplinary Team of Analytical Sciences for Sustainable Development, University Sultan, Morocco

${ }^{2}$ Molecular Electrochemistry and Inorganic Materials Team, Sultan Moulay Slimane University, Beni Mellal Faculty of Science and Technology, Morocco

\begin{abstract}
Cyclic voltametry (CV) and Square wave voltametry (SWV) were used to study the electrochemical behavior and evaluate the antioxidant capacity of virgin olive oil. Firstly, in this work we illustrate the electrochemical methods based on the preparation and characterization of $\mathrm{H}_{2} \mathrm{O}_{2}$ amperometric sensor, then the antioxidant capacity of the virgin olive oil was evaluated by measuring of the of virgin olive oil effect on the $\mathrm{H}_{2} \mathrm{O}_{2}$ reduction.
\end{abstract}

Keywords: Olive oil; Antioxidant capacity; Cyclic voltammetry; Square wave voltammetry

\section{Introduction}

The major components of olive oil are: oleic acid, phenolic constituents and squalene. The main phenolics include hydroxytyrosol, tyrosol, and oleuropein, which occur in highest levels in virgin olive oil and have demonstrated antioxidant activity. Oxidative stress caused by production of reactive oxygen species is linked to various pathological conditions [1]. Several authors have shown that free radicals lead to the pathogenesis of a various disease including diabetes, hypertension, inflammation and cancer [2]. Reactive oxygen species (ROS), naturally generated during the metabolism, can damage biological structures such as proteins, lipids or DNA. Normally, cells defend themselves against ROS damage with enzymes, but sometimes the natural defenses are overwhelmed by an excessive generation of ROS and a situation of oxidative stress occurs. In this case, cellular and extracellular macromolecules (proteins, lipids, and nucleic acids) can suffer oxidative damage, causing tissue injury $[3,4]$.

A wide variety of electrochemical sensors and biosensors have already been proposed for antioxidant capacity evaluation [5-14]. Most of them are based on the amperometric detection of $\mathrm{H}_{2} \mathrm{O}_{2}$, resulting from the catalyzed dismutation of superoxide radicals $\left(\mathrm{O}_{2}{ }^{-}\right)$in presence of superoxide dismutase. The purpose of this work was to investigate the electrochemical properties of antioxidants contained in virgin olive oil, using copper modified carbon paste electrode, site of oxidative reduction reactions.

\section{Experiment Section}

\section{Apparatus}

Electrochemical measurements were recorded on a Voltalab potentiostat instrument (model PGSTAT 100, Eco Chemie B. V., Utrecht, The Netherlands) driven by the general purpose electrochemical systems data processing software (voltalab master 4 software). The cell was equipped with a copper modified carbon paste electrode $(\mathrm{Cu}-$ $\mathrm{CPE}$ ), a platinum electrode of a larger area and an $\mathrm{Ag} / \mathrm{AgCl}$ reference electrode.

\section{Reagents and solutions}

All chemicals were of the highest quality. Graphite powder (spectroscopic grade RWB, Ringsdorff-Werke GmbH, Bonn-Bad Godesberg, Germany) was obtained from Aldrich and was used without further purification. $\mathrm{CuSO}_{4}$ was obtained from Merck chemicals.
Deionised water was used to prepare all solution.

\section{Preparation of the $\mathrm{Cu}-\mathrm{CPE}$}

The carbon paste unmodified was prepared by adding paraffin oil to carbon powder and thoroughly hand-mixing in a mortar. The resulting paste was packed into the electrode and the surface was smoothed. The modified electrode was developed by depositing the copper at fixed potential $(0.1 \mathrm{~V}$ for $1 \mathrm{~h})$ onto the carbon paste electrode surface.

\section{Results and Discussion}

Cyclic voltammograms of $\mathrm{Cu}-\mathrm{CPE}$ is recorded in the electolytical solution $0.1 \mathrm{M} \mathrm{Na}_{2} \mathrm{SO}_{4}$ at scan rate of $100 \mathrm{mV} / \mathrm{s}$ is shown in Figure 1. It is a typical voltammogram of copper, which shows two redox peaks, the first one in the direction of the cathodic scan, at about $-0.9 \mathrm{~V}$, and the second one, in the opposite direction at $-0.2 \mathrm{~V}$.

The EIS experiments were carried out in $0.1 \mathrm{~mol} \mathrm{~L}^{-1} \mathrm{Na}_{2} \mathrm{SO}_{4}$ in order to confirm the mechanisms suggested in the voltammetric part of this work regarding the $\mathrm{Cu}-\mathrm{CPE}$ interaction. Figure 2 shows the Nyquist plot for $\mathrm{Cu}$-modified electrode included a semicircle at higher frequencies corresponding to the electrontransfer limited process and the linear part at lower frequencies corresponding to the diffusion process.

The surface structure of copper modified carbon paste surface was observed using scanning electron microscopy (Figure 3 ). The film layer of copper was formed on the surface of carbon paste electrode; it was not disintegrated or detached from the surface when immersed in the electrolytic solution. The surface has a porous shape and constitutes by clusters of copper of different dimensions, forming a rough film.

First, we plotted the calibration curve, of $\mathrm{H}_{2} \mathrm{O}_{2}$ from the SWV recorded at $\mathrm{Cu}$-CPE in $0.1 \mathrm{M} \mathrm{Na}_{2} \mathrm{SO}_{4}$, containing various concentrations

*Corresponding author: Chtaini A, Molecular Electrochemistry and Inorganic Materials Team, Sultan Moulay Slimane University, Beni Mellal Faculty of Science and Technology, Morocco, Tel: 212661118521; E-mail: a.chtaini@usms.ma

Received January 19, 2017; Accepted February 10, 2017; Published February 20, 2017

Citation: Mourhat Z, Touzara S, Maallah R, Mbarki M, Chtaini A (2017) Electrochemical Evaluation of the Antioxidant Capacity of Phenolic Compounds in Virgin Olive Oil. J Biosens Bioelectron 8: 237. doi: 10.4172/2155-6210.1000237

Copyright: @ 2017 Mourhat Z, et al. This is an open-access article distributed under the terms of the Creative Commons Attribution License, which permits unrestricted use, distribution, and reproduction in any medium, provided the original author and source are credited. 


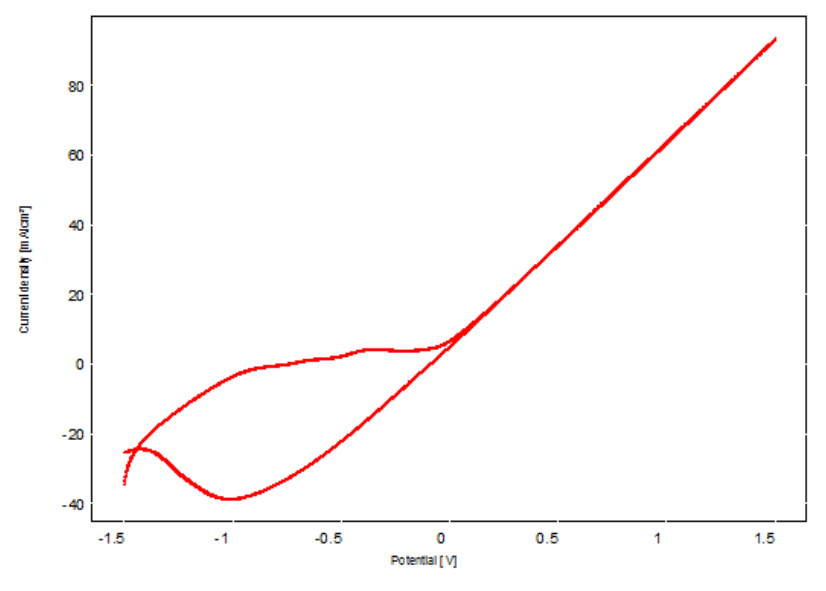

Figure 1: Cyclic voltammograms recorded at $\mathrm{Cu}-\mathrm{CPE}$ in $0.1 \mathrm{M} \mathrm{Na} \mathrm{SO}_{4}$ solution, scan rate $100 \mathrm{mV} / \mathrm{s}$.

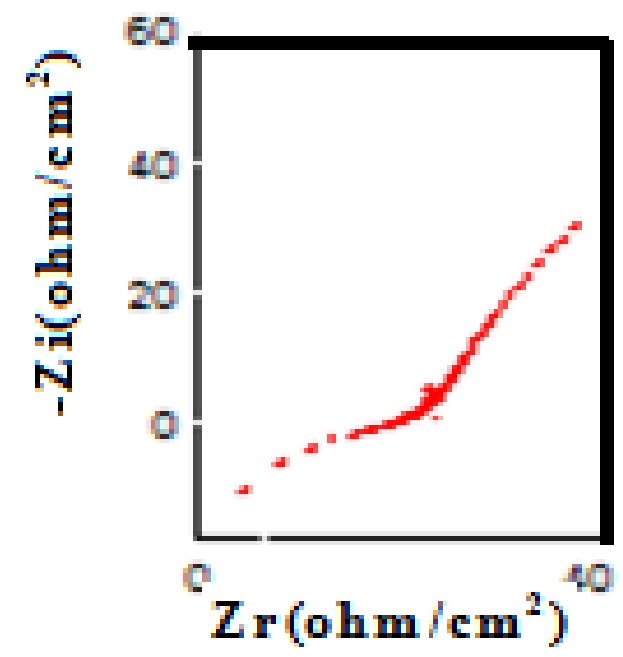

Figure 2: EIS diagrams recorded at $\mathrm{Cu}-\mathrm{CPE}$ in $0.1 \mathrm{M} \mathrm{Na}_{2} \mathrm{SO}_{4}$ solution.

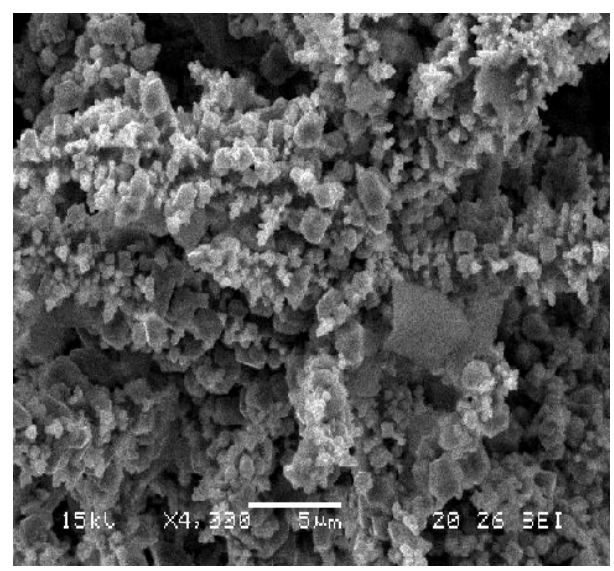

Figure 3: Scanning Electron Micrograph of Cu-CPE. of $\mathrm{H}_{2} \mathrm{O}_{2}$. The square wave voltammetric response was almost linear dependent on the radical oxygen concentration (Figure 4).

After the addition of $350 \mu \mathrm{l} / 100 \mathrm{ml}$ of the sample (Virgin olive oil -VOO-), the $\mathrm{H}_{2} \mathrm{O}_{2}$ reduction current density decreases (Figure 5), subsequently leading to a decrease in free radical concentration in the solution, which leads to the conclusion that VOO inhibits Oxidizing capacity of $\mathrm{H}_{2} \mathrm{O}_{2}$.

Figure 6 shows the performance of the copper modified carbon paste electrode in the presence of antioxidant $(350 \mu \mathrm{L}$ of virgin olive oil) and the hydroxyl radical $(50 \mu \mathrm{l})$. To perform the electrochemical study all current peaks were compared with the signal current obtained with the $\mathrm{H}_{2} \mathrm{O}_{2}$. The electrochemical reduction of radical is manifested in square wave volatammetry by a defined peak at around $-0.6 \mathrm{~V}$. The addition of the antioxidant sample to the solution containing the free radical causes the decrease in the current density of this peak [14-18].

The $\mathrm{H}_{2} \mathrm{O}_{2}$ reduction current density decreases with increasing the amount of the antioxidant sample (VOO) (Figure 7). The square wave voltammetric response was almost linear dependent on the concentration of sample (VOO) (Figure 8). The linear regression analysis gave:

I $\left(\mathrm{mA} / \mathrm{cm}^{2}\right)=-0.003$ [sample] +2.306 with a correlation coefficient of 0.988

The corresponding antioxidant capacity values, was calculated using the relation:

$$
\text { AOC }=\frac{\mathrm{I}_{\mathrm{H} 202}-\mathrm{I}_{\mathrm{H} 202} \text { presence of antioxidant sample }}{\mathrm{I}_{\mathrm{H} 2 \mathrm{o} 2}} \times 100
$$

Where $\mathrm{I}_{\mathrm{H}_{2} \mathrm{O}_{2}}$, is the current density due to $\mathrm{H}_{2} \mathrm{O}_{2}$ reduction and $\mathrm{I}_{\mathrm{H}_{2} \mathrm{O} 2}$ antioxidant sample represent the current density due to antioxidant sample addition.

In this work we calculated and compared the antioxidant capacities of several samples of virgin olive oil, collected on different sites of the Tadla Azilal region, Morocco. The results are shown in the following histogram (Figure 9)

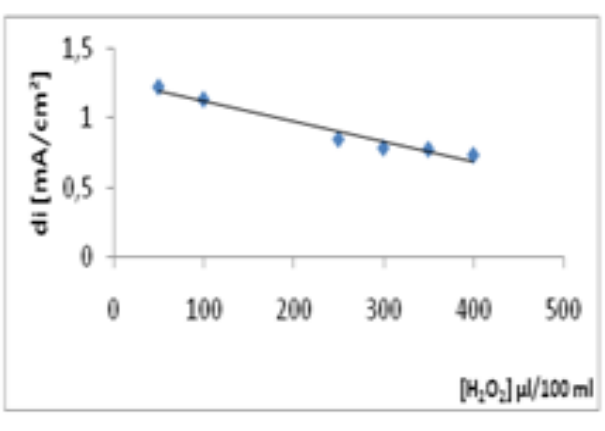

Calitimangrabi

Figure 4: Calibration graph. 


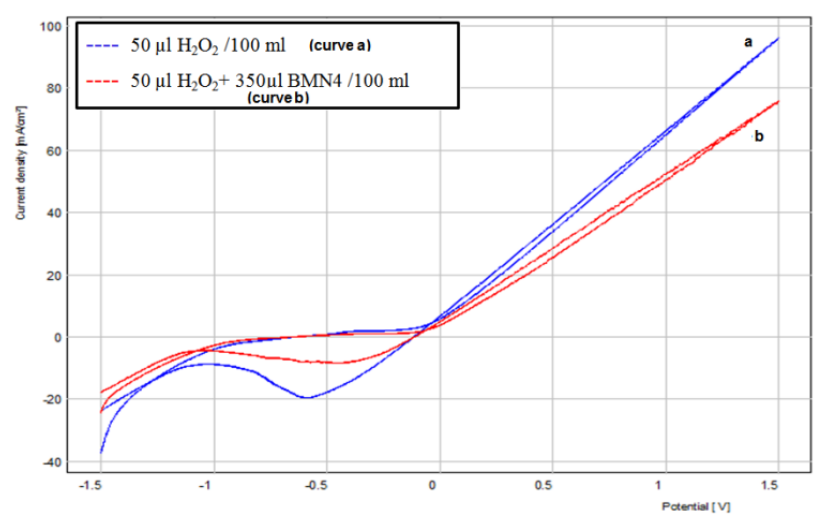

Figure 5: Cyclic voltammograms recorded at Cu-CPE, in CPE in $0.1 \mathrm{M} \mathrm{Na}_{2} \mathrm{SO}_{4}$ solution containing $\mathrm{H}_{2} \mathrm{O}_{2}$, a- in absence of $\mathrm{VOO}$, b- in presence of VOO.

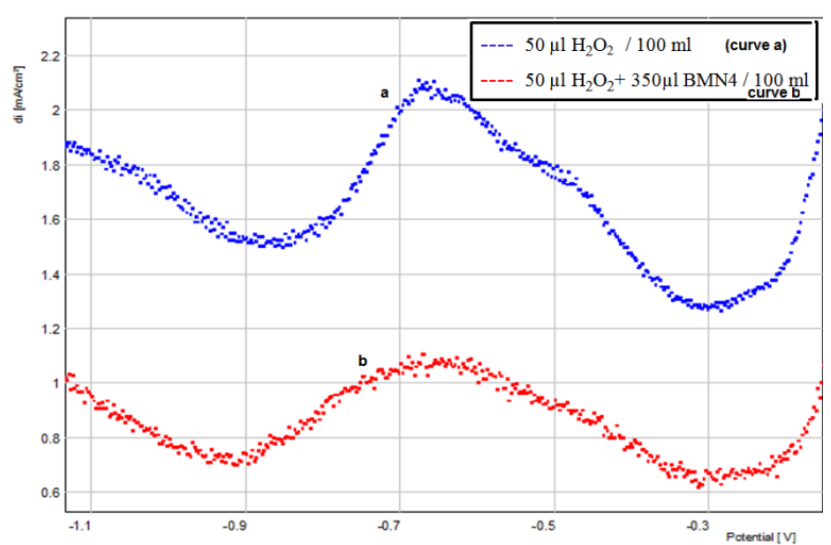

Figure 6: Square wave voltammograms recorded at $\mathrm{Cu}-\mathrm{CPE}$, in $\mathrm{CPE}$ in 0.1 $\mathrm{M} \mathrm{Na}_{2} \mathrm{SO}_{4}$ solution containing $\mathrm{H}_{2} \mathrm{O}_{2}$, a- in absence of VOO, b- in presence of $\mathrm{VOO}$.

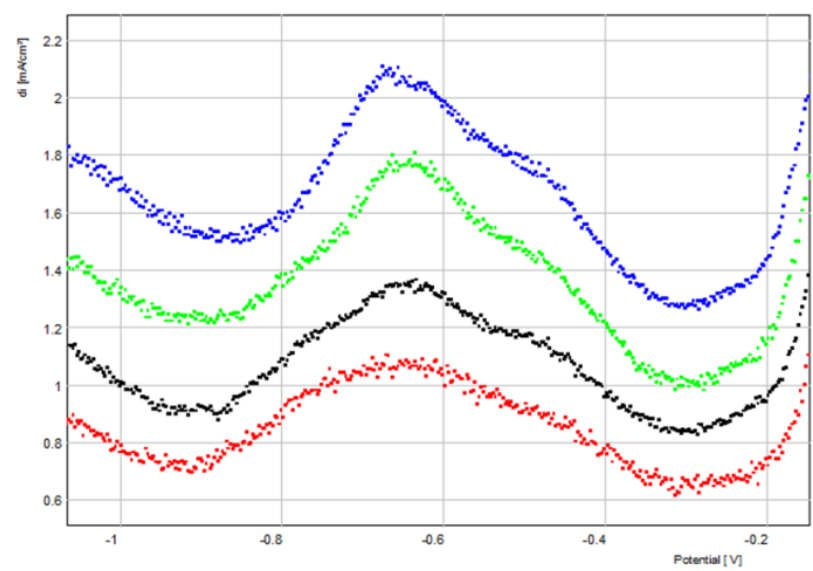

Figure 7: Square wave voltammograms recorded at $\mathrm{Cu}-\mathrm{CPE}$, in $\mathrm{CPE}$ in $0.1 \mathrm{M}$ $\mathrm{Na}_{2} \mathrm{SO}_{4}$ solution containing $\mathrm{H}_{2} \mathrm{O}_{2}$. Effect of the VOO.

\section{Conclusion}

A copper modified copper electrode for the AOC quantification of a variety of virgin olive oil was prepared and characterized in electrolytic

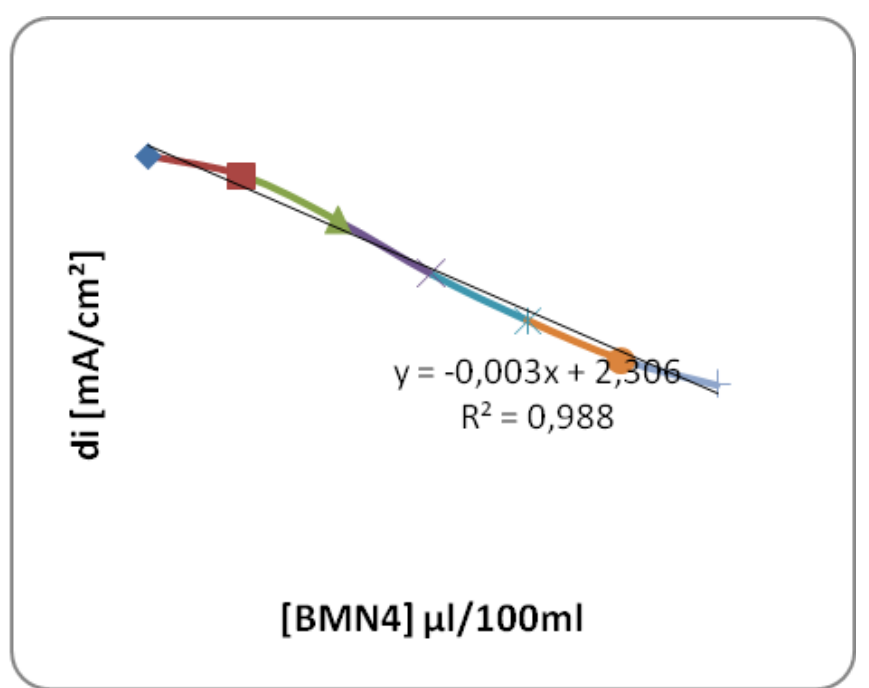

Figure 8: Evolution of the $\mathrm{H}_{2} \mathrm{O}_{2}$ reduction current density with the concentration of VOO.

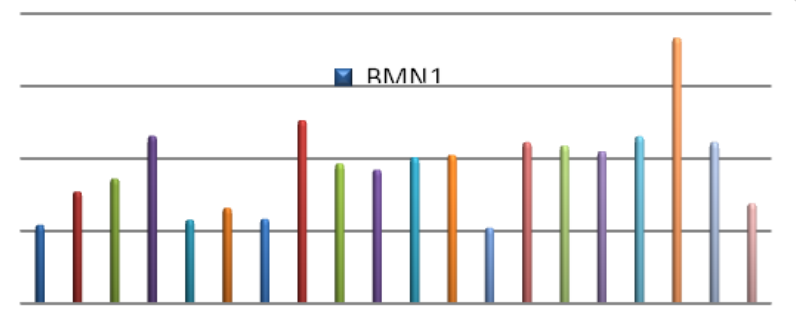

Samples

Figure 9: Comparison of $\mathrm{AOC}$ of $\mathrm{VOO}$ collected on different sites of the TadlaAzilal region.

media. First, a calibration curve is determined from the relationship between the reduction current density of $\mathrm{H}_{2} \mathrm{O}_{2}$ and $\left[\mathrm{H}_{2} \mathrm{O}_{2}\right]$. The virgin olive oil had the capacity to inhibit the superoxide radical reduction which is responsible for the oxidation of the cells, causing subsequent oxidative stress. Several virgin olive varieties have been tested and their AOCs have been determined, these samples harvested at different sites in the Tadla Azilal region, Morocco. The largest AOC has exceeded the lowest of the order of $20 \%$.

\section{References}

1. Valko M, Leibfritz D, Mancol J, Cornin MTD, Mazur M, et al. (2007) Free radicals and antioxidants in normal physiological functions and human disease. Int J Biochem Cell Biol 39: 44-84.

2. Halliwell B (1994) Free radicals, antioxidants, and human disease: curiosity, cause, or consequence? The Lancet 344: 721-724.

3. Mello L, Kubota L (2007) Biosensors as a tool for the antioxidant status evaluation. Talanta 72: 335-348.

4. Campanella L, Bonnani A, Finotti E, Tomassetti M (2004) Biosensors for determination of total and natural antioxidant capacity of red and white wines: Comparison with other spectrophotometric methods. Biosens Bioelectron 19: 641- 651 .

5. Campanella L, Favero G, Persi L, Tomassetti M (1999) Superoxide Dismutase Biosensors for Superoxide adical Analysis. Anal Lett 32: 2559-2581.

6. Bonnani A, Campanella L, Gatta T, Tomassetti M (2007) Evaluation of the 
Citation: Mourhat Z, Touzara S, Maallah R, Mbarki M, Chtaini A (2017) Electrochemical Evaluation of the Antioxidant Capacity of Phenolic Compounds in Virgin Olive Oil. J Biosens Bioelectron 8: 237. doi: 10.4172/2155-6210.1000237

antioxidant and prooxidant properties of several commercial dry spices by different analytical methods. Food Chem 102: 751-758.

7. Campanella L, Bonnani A, Favero G, Tomassetti M (2003) Determination of antioxidant properties of aromatic herbs, olives and fresh fruit using an enzymatic sensor. Bioanal Chem 375: 1011-1016.

8. Di J, Bi S, Zhang M (2004) Surface plasmon resonance immunosensor for the detection of Salmonella typhimurium. Biosens Bioelectron 19: 1497-1486.

9. Tiam Y, Okajima T, Kitamura F, Ohsaka T (2002) A SOD-Based Amperometric Biosensor for Superoxide Ion. J Korean Electrochem Soc 5: 212-215.

10. Emregul E (2005) Development of a new biosensor for superoxide radicals. Anal Bioanal Chem 383: 947-954.

11. Mesaros S, Vankova Z, Mesarosova A, Tomcik P, Grufeld S (1998) Electrochemical determination of superoxide and nitric oxide generated from biological samples. Bioelectrochem Bioenergy 46: 33-37.

12. Ignatov S, Shishniashvili D, Ge B, Scheller F, Lisdat F (2002) Amperometric biosensor based on a functionalized gold electrode for the detection of antioxidants. Biosens Bioelectron 17: 191-199.
13. Lisdat F, Ge B, Rezeka R, Kozniewska E, Fresentius (1999) J Anal Chem 365: 494-498.

14. Beissenhirtz M, Scheller F, Lisdat F (2003) Immobilized Cytochrome c Sensor in Organic/Aqueous Media for the Characterization of Hydrophilic and Hydrophobic Antioxidants. Electroanal 15: 1425-1435.

15. Cervantes MI, Balderas PM, Banos JJ, Ibarra BO, Rojas BF, et al. (2013) Comparaison of antioxidant activity of hydroethanolic fresh and aged garlic extraxts and their effects on cerebral ischemia. Food Chemistry 140: 343-352.

16. Aguilera P, Cardenas ME, Plata AO, Aparicio DL, Barrera D, et al. (2010) Aged garlic extract delays the appearance of infarct area in a cerebral ischemia model, an effect likely conditioned by the cellular antioxidant systems. Phytomedecine 17: 241-247.

17. Mousa S, Mousa SA (2007) Cellular effects of garlic supplements and antioxidant vitamins in lowering marginally high blood pressure in humans: pilot study. Nutrition Research 27, 119-123.

18. Alsabri SG, El-Basir HM, Rmeli NB, Mohamed SB, Allafi AA, et al. (2013) Phytochemical screening, antioxidant, antimicrobial and anti-proliferative activities study of Arbutus pavarii plant. Journal of Chemical and Pharmaceutical Research 5:32-36. 